\title{
ELEMENTOS TEÓRICO-METODOLÓGICOS PARA A FORMAÇÃO DE PROFESSORES NA PERSPECTIVA DA EDUCAÇÃO POPULAR
}

\author{
THEORETICAL-METHODOLOGICAL ELEMENTS FOR TEACHER TRAINING \\ UNDER THE POPULAR EDUCATION PERSPECTIVE
}

\author{
Matheus Bernardo Silva \\ Doutor em Educação - UNICAMP. \\ Universidade do Sul de Santa Catarina - UNISUL. \\ Instituto Ânima - IA. \\ Tubarão, Santa Catarina - Brasil. \\ matheus.bernardo@animaeducacao.com.br
}

\begin{abstract}
Resumo: O presente texto tem como objetivo apresentar uma discussão sobre a formação de professores a partir de uma perspectiva da educação popular. Como hipótese, acredita-se que a formação de professores em prol de uma transformação social deve estar atrelada aos interesses da classe subalterna. Para tanto, o processo educativo implica em uma atividade educacional sistematizada, cuja concepção de mundo se dá por meio de uma prática transformadora. Refere-se, portanto, a uma pesquisa de cunho teórico-bibliográfico, utilizando, principalmente, o aporte teórico-metodológico da pedagogia histórico-crítica, em especial, a produção de Dermeval Saviani. A hipótese é confirmada a partir do aporte teórico-metodológico, pois o desenvolvimento de uma consciência de classe ocorre por meio da apropriação, pelos membros da classe subalterna, do conhecimento historicamente sistematizado, partindo de uma compreensão política da situação atual, que é condição imprescindível para a transformação social.
\end{abstract}

Palavras-chave: atividade educacional sistematizada; consciência crítica; educação popular; formação de professores.

\begin{abstract}
This text has as aim at presenting a discussion on teacher training from a popular education perspective. As hypothesis, we believe that teacher training in favor of a social transformation should be coupled up with the subordinate class interests. Thereunto, educational process implies a systematized education activity, whose world's conception occurs through a transformative practice. Therefore, it reflects theoretical-methodological research, especially using the production by Dermeval Saviani. The hypothesis is confirmed from the theoreticalmethodological contributions because developing class consciousness happens through appropriation, by the subordinate class members, of the historically systematized knowledge from understanding the current politics which is a paramount condition for social transformation.
\end{abstract}

Keywords: systematized education activity; critical consciousness; popular education; teacher training.

\section{Para citar - (ABNT NBR 6023:2018)}

BERNARDO SILVA, Matheus. Elementos teórico-metodológicos para a formação de professores na perspectiva da educação popular. Eccos - Revista Científica, São Paulo, n. 59, p. 1-18, e11579, out./dez. 2021. Disponível em: https://doi.org/10.5585/eccos.n59.11579. 


\section{Considerações iniciais}

Refletir sobre a formação de professores em uma perspectiva crítica é uma tarefa complexa que merece constantes aprofundamentos, especialmente quando partimos do princípio que a atividade educativa é sempre um ato político que incide na consciência do educando.

Trata-se de um ato político, porque o processo educativo está sempre atrelado (condicionado) às condições histórico-sociais, ou seja, tal processo influencia e é influenciado pela sociedade vigente. Mediante isso, é importante dizer que numa sociedade de classes, como é a sociedade brasileira, a atividade educativa pode contribuir, apenas, com um dos interesses sociais que estão em jogo: os da classe dirigente ou os da classe subalterna.

É nesse sentido que o presente manuscrito versa, isto é, apresenta uma possível maneira de refletir sobre as especificidades da formação de professores na perspectiva dos interesses da classe subalterna. Por meio de uma pesquisa teórico-bibliográfica, no que tange ao aspecto teórico-metodológico, utilizamos determinados elementos da teoria pedagógica históricocrítica, em especial, a partir da produção de Dermeval Saviani.

Como desdobramento, a problemática é apresentada em três momentos: 1) na discussão teórica que expõe apontamentos que evidenciam o processo educativo como um ato político; 2) na reflexão sobre a precisão da expressão educação popular na perspectiva do povo e pelo povo; 3) na apresentação de elementos sobre a legitimidade da atividade educacional sistematizada em proveito de uma formação de professores em uma perspectiva da classe subalterna.

\section{Notas sobre o processo educativo como um ato político}

Sabe-se que o trabalho é a categoria cabal para a produção e manutenção da existência humana. É por meio do processo de transformação da natureza, de maneira consciente, criativa e intencional, que o ser humano produz a sua existência. A esse processo podemos denominar de trabalho, que é, uma atividade especificamente oriunda da espécie humana.

Assim como o trabalho, a educação é uma atividade específica do ser humano. Isso significa dizer que ele não nasce ser humano, mas forja-se ser humano na sua relação consciente, intencional e criativa com a natureza. Portanto, o ser humano precisa aprender a produzir a sua própria existência como condição sine qua non para a sua sobrevivência, tendo em vista que a sua produção “[...] é, ao mesmo tempo, a formação do homem, isto é, um 
processo educativo. A origem da educação coincide, então, com a origem do homem mesmo" (SAVIANI, 2007, p. 154).

A gênese da educação está relacionada ao ato humano de produzir a própria existência. A validade das formas e conteúdos desenvolvidos no ato de trabalhar se dá pela pertinência, na própria experiência. Consequentemente, os procedimentos, conteúdos e instrumentos validados pela experiência necessitam ser preservados e transmitidos às gerações ulteriores. Eis aí o ensejo de o ser humano produzir sua existência historicamente e desenvolvê-la socialmente no decorrer dos tempos. Logo, o modo de produção da existência humana é o fator fundamental para poder caracterizar a educação.

A relação entre trabalho e educação, conforme adverte Saviani (2007), é, ao mesmo tempo, uma correlação histórica, pois está inserida no progressivo movimento de produção e desenvolvimento da existência humana. E, ao mesmo tempo, é uma correlação ontológica, pois o resultado dessa produção e desse desenvolvimento é a própria essência do ser humano.

Observa-se, em linhas gerais, a relação intrínseca entre trabalho e educação. Destarte, o processo educativo estará sempre articulado com o processo de produção da existência humana. Nesse caso, o processo educativo está inserido no modo de produção capitalista, o qual regimenta a sociedade que vivemos, conforme se observa atualmente.

Assim, constitui-se uma determinada concepção hegemônica de educação que, em última instância, busca, numa acepção gramsciana, "educar o consenso". Isso porque a concepção de educação hegemônica hodierna vem se concretizando, em termos cada vez mais avançados, para sanar as demandas do atual estágio do modo de produção capitalista, cujo momento encontra-se em uma acentuada crise estrutural.

Portanto, a educação direcionada para a maioria dos indivíduos, ou seja, para a classe subalterna (trabalhadora), tem como principal essência a formação de um trabalhador "competente", "flexível" e "dócil" frente às necessidades dinâmicas do mercado de trabalho. Trata-se, portanto, de adestrar o trabalhador para a sociedade regimentada pela mercadoria, inclusive o próprio trabalhador torna-se uma mercadoria.

Segundo Frigotto (2012, p. 21), no que se refere a concepção de trabalho hegemônica: 


\begin{abstract}
A concepção burguesa de trabalho vai-se construindo, historicamente, mediante um processo que o reduz a uma coisa, um objeto, a uma mercadoria que aparece como trabalho abstrato em geral, força de trabalho. Essa interiorização vai se estruturando uma percepção ou representação de trabalho que se iguala à ocupação, emprego, função, tarefa, dentro de um mercado (de trabalho). Dessa forma, perde-se a compreensão, de um lado, de que o trabalho é uma relação social e que esta relação, na sociedade capitalista é uma relação de força de poder e de violência; e, de outro, de que o trabalho é a relação social fundamental que define o modo humano de existência, e que, enquanto tal, não se reduz à atividade de produção para responder à reprodução físico-biológica (mundo da necessidade), mas envolve as dimensões sociais, estéticas, culturais, artísticas, de lazer etc. (mundo da liberdade).
\end{abstract}

Em consequência, ao ser relacionada com a concepção de trabalho advinda da classe dirigente (burguesa), a educação é compreendida como um direito universal, porém no bojo de uma igualdade abstrata. Seguindo na reflexão de Frigotto (2012), a classe dirigente procura, por meio de todos os elementos sociais possíveis - inclusive pelo próprio Estado, por exemplo incutir na consciência dos membros da classe subalterna os seus próprios interesses, ou seja, procura universalizar os seus interesses. Nesse sentido, procura-se enraizar no conceito de trabalho como se o mesmo fosse "[...] uma atividade que cria indistintamente para todos" (FRIGOTTO, 2012, p. 23). Com isso, é somente pela via do trabalho severo, da disciplina, da submissão, que o trabalhador terá uma suposta condição de se apropriar das riquezas já acumuladas pelo patrão (dirigente) e, assim, tornar-se também um patrão. Conforme afirmou Frigotto (2012, p. 23) "O trabalho aparece como uma virtude universal, pela qual a acumulação do capital é legítima".

Em função disso, busca-se naturalizar o processo competitivo desenfreado e as exigências individualistas que regem as leis do mercado. Como consequência, introduz-se, por todos os meios possíveis, inclusive e principalmente pela educação, a naturalização e vulgarização de uma constante especialização, por parte do trabalhador. Tal processo lhe permite estar assiduamente comprometido com as leis do mercado. $\mathrm{O}$ que o torna propenso a uma determinada atividade, no processo de trabalho, que o obrigue a operar, ao mesmo tempo, diversas funções. Eis aí a flexibilidade e a polivalência que devem ser assimiladas como natural pelos trabalhadores, para que possam estar à disposição do mercado de trabalho, ou melhor, para que possam servir para aquilo que a "mão invisível" do mercado de trabalho solicita em qualquer momento.

Assim como em todo processo histórico do modo de produção capitalista, o desenvolvimento das capacidades psicofísicas dos trabalhadores é efetivado de forma unilateral, a fim de atender as demandas do processo de produção que se rege pela divisão do trabalho, ou seja, pela divisão do trabalho entre manual e intelectual. Alves (2012, p. 111) 
argumenta que ocorre, no interior desse processo de produção e de trabalho, uma "captura" da subjetividade do trabalhador. 'Na nova produção do capital, o que se busca 'capturar' não é apenas o 'fazer' e o 'saber' dos trabalhadores, mas a sua disposição intelectual-afetiva, constituída para cooperar com a lógica da valorização".

Perpetua-se, de forma cada vez mais severa, a concepção de mundo burguesa, onde toda a riqueza humana, inclusive os próprios homens, torna-se em mercadorias. Ideologicamente, fragmenta-se a relação entre aparência e essência, estabelecendo a opacidade nas relações sociais, o que, por conseguinte, concorre para o apaziguamento entre as classes sociais.

Em contrapartida, podemos observar a concepção de educação da pedagogia históricocrítica, alinhada com a concepção de ser humano (e de mundo) marxista, aponta que o processo de produção da existência humana ocorre, inicialmente, para assegurar a subsistência material dos homens. Esse processo de produção dos bens materiais se torna, no decorrer do tempo, cada vez mais amplo e complexo. A esse processo, Saviani (2013b), caracteriza como "trabalho material".

Não obstante, para que o ser humano tenha condição de concretizar o trabalho material é necessário que antecipe, no seu pensamento, os objetivos e os fins da atividade material. Ou seja, por meio das condições dispostas pela evolução do psiquismo humano, ele antecipa, mentalmente, a atividade que irá realizar materialmente. O suprassumo da atividade humana, isto é, o trabalho, depende e, ao mesmo tempo, está intrinsecamente relacionado com o conhecimento que o ser humano possui das propriedades do planeta (ciência), com a valoração dos dados da realidade concreta (ética) e com a simbolização de tal realidade (arte). Estes são, portanto, elementos essenciais para o constante processo de trabalho, a que se denomina “trabalho não material”. Trata-se, conforme Saviani (2013b, p. 12), da “[...] produção de ideias, conceitos, valores, símbolos, hábitos, atitudes, habilidades. Numa palavra, trata-se da produção do saber, seja do saber sobre a natureza, seja do saber sobre a cultura, isto é, o conjunto da produção humana".

A educação, para a pedagogia histórico-crítica, está situada no âmbito do trabalho não material. Essa categoria, por um lado, se refere às atividades nas quais o produto se separa do produtor (como é o caso da produção de livros e objetos artísticos, por exemplo), ou seja, há uma separação entre o ato de produzir e o de consumir, compreendendo a autonomia entre o produto e o ato de produção. Do outro lado, se refere às atividades em que o produto não se separa do ato de produção, isto é, os atos de produção e de consumo estão articulados, não se separam. Diante disso, vale ressaltar que a educação situa-se na segunda modalidade do trabalho não material. Nas palavras de Saviani (2013b, p. 12): “Com efeito, se a educação, 
pertencendo ao âmbito do trabalho não material, tem a ver com ideias, conceitos, valores, símbolos, hábitos, atitudes, habilidades, tais elementos, entretanto, não lhe interessam em si mesmos, como algo exterior ao homem".

A pedagogia histórico-crítica propõe um sistema de ensino numa perspectiva socialista, cujo enfoque é de aprofundamento dos conhecimentos até o seu grau mais complexo, desde o nível fundamental (básico) até o superior. Por consequência, já no nível fundamental ela postula a necessidade de que o aluno se aproprie dos conhecimentos que englobam a linguagem escrita, a matemática, as ciências naturais e as ciências sociais, não em um sentido abstrato e ahistórico, mas, principalmente, enfatizando o "sentido de classe" como significado social do conhecimento. É por meio do ingresso na escola, começando pelo ensino fundamental, que o indivíduo inicia o processo de acesso ao saber elaborado.

Para a pedagogia histórico-crítica, o que está em pauta é a passagem do senso comum à consciência filosófica, tendo a educação escolar como instrumento de mediação para tal processo. É condição sine qua non da educação escolar contribuir para que o trabalhador possa dar um salto qualitativo na forma de conceber e estar na sociedade. Isto é, fazer com que o trabalhador problematize a realidade em que está inserido, observe a desigualdade social e, prosseguindo, conclua que há a possibilidade de outra realidade, onde ele seja capaz de se tornar, de fato, um cidadão, um "homem humano" (humanizado), como síntese daquilo que de mais avançado a humanidade produziu historicamente e desenvolveu socialmente.

Ora, o que constatamos até aqui nada mais é do que a educação como um ato político, visto que o processo educativo somente tem condição de aderir a um interesse social: do dirigente (como é o caso da concepção burguesa de educação) ou do subalterno (como é o caso da pedagogia histórico-crítica). Em outras palavras: o processo educativo somente pode estar a serviço do capital ou dos trabalhadores, ou seja, não há uma neutralidade. "É isso que se quer dizer quando se afirma que a educação é um ato político" (SAVIANI, 2015, p. 106). A educação como um ato político indica que a mesma está relacionada com a sociedade, pois a educação é determinada pela sociedade. "E quando a sociedade é dividida em classes cujos interesses são antagônicos, a educação serve a interesses de uma ou de outra das classes fundamentais" (SAVIANI, 2015, p. 106).

Assim, estabelecendo os elementos da pedagogia histórico-crítica como princípio educativo, passaremos, no momento seguinte, a discutir as especificidades da educação popular a serviço dos interesses da classe subalterna, ou seja, de uma educação que vai além de uma educação popular da classe dirigente direcionada para os trabalhadores. 


\section{Apontamentos para uma precisão no conceito de educação popular}

Ao nos debruçarmos nas entrelinhas da história da educação brasileira, podemos observar que o conceito educação popular teve um destaque já na Primeira República, ao articular-se com o movimento de implantação dos sistemas nacionais de ensino que ocorreu no decorrer do século XIX em diversos países.

De acordo com Saviani (2011), a expressão educação popular estava alinhavada com o processo designado a instrução elementar - via a escola primária -, cujo intuito seria a generalização de tal instrução para a população de cada nação. Confundia-se ou coincidia-se, por conseguinte, com o conceito de instrução pública. Eis aí a estratégia de conseguir efetivar a erradicação do analfabetismo.

No Brasil, principalmente a partir da década de 1920, urgiu como discussão a necessidade sobre o aumento das escolas primárias, com o objetivo, justamente, de sanar o analfabetismo da população. Estava em voga o direcionamento para um olhar nacionalista com ênfase, por parte da classe dirigente (ideologia de direita), no civismo e no patriotismo. Já no que tange ao movimento de esquerda no país, nesse período, tanto via a lógica anarquista como a lógica comunista apresentava-se como definição o termo internacionalista.

Depois das ações instituídas na Revolução de 1930, no Brasil, em consonância com a expansão do movimento de industrialização do país, junto com a mobilização das massas, o aspecto social passou a ser direcionado para a política nacional. "O desenvolvimento nacional passou a ser ideia-guia, dando azo à manifestação da ideologia que veio a ser identificada pelo nome de "nacional-desenvolvimentismo"” (SAVIANI, 2011, p. 311), chegando a tal ponto de criar uma instituição para instituir as especificidades dessa ideologia: o Instituto Superior de Estudos Brasileiros (ISEB).

Portanto, o movimento nacional-desenvolvimentista que se estendeu no decorrer da década de 1950 chegando até o início da década posterior teve, também, influência no âmbito da educação brasileira. Naquele contexto, nota-se que as ações de Anísio Teixeira tornaram-se cabais, no tocante a um modelo de educação que atuasse em proveito do desenvolvimento industrial brasileiro. ${ }^{1}$ Destarte, para Anísio era necessário conscientizar a população brasileira sobre a modernização da sociedade, isto é, era necessário legitimar na sociedade que todos dirigentes e subalternos - poderiam viver em conjunto, extinguindo a fragmentação social em prol do nacionalismo, no fortalecimento da nação brasileira. E, conforme Saviani (2011, p. 316)

\footnotetext{
${ }^{1}$ Conforme Lima (2018, p. 47-48), "O educador que melhor expressou a influência do nacional-desenvolvimentismo sobre a educação foi Anísio Teixeira, tradutor de Dewey em terras brasileiras, criando em 1955 o Centro Brasileiro de Pesquisas Educacionais (CBPE), mesmo ano em que fora criado o ISEB, órgão do qual participou diretamente, assumindo o papel no Conselho Curador".
} 
interpreta o posicionamento de Anísio, “[...] o instrumento para atingir-se esse nível de consciência é exatamente a escola, pois só ela, na medida em que se constituir, de fato, como o lugar do estudo e do conhecimento do Brasil, poderá mostrar o caminho da emancipação nacional $[\ldots] "$.

Consequentemente, a vigência da ideia de desenvolvimento da nação brasileira e sua relação com a política populista evidenciavam uma certa mobilização, especialmente, da classe subalterna. Destaque-se que, naquele contexto, os políticos dependiam inexoravelmente do apoio dessa classe para poder ter sucesso nas eleições. Porém, como sabemos a condição de o indivíduo votar se dava a partir do mesmo ter sido alfabetizado. Assim, diversas campanhas foram inauguradas, via o governo, para alfabetizar jovens e adultos, tanto da área urbana quanto da área rural. Tais campanhas "[...] consideravam a educação popular no sentido até então dominante, isto é, abrangendo as questões relativas à instrução pública, isto é, a educação elementar destinada seja às crianças (ensino primário), seja aos adultos (programas de alfabetização)" (SAVIANI, 2011, p. 316).

Todavia, podemos destacar que o Movimento de Educação de Base (MEB), instituído pelo presidente Jânio Quadros, estava sob responsabilidade da Igreja Católica, ou seja, dirigido pela Confederação Nacional dos Bispos do Brasil (CNBB), mas o direcionamento e a execução eram designados para indivíduos leigos. Contudo, tais indivíduos se afastaram dos objetivos oriundos da Igreja Católica, direcionando-se para um movimento de conscientização e, consequentemente, de politização das massas.

Portanto, no bojo da década de 1960 há uma inversão no sentido dominante atribuído a educação popular. Com isso, a educação passou a ser compreendida como um mecanismo de conscientização da classe subalterna, sobre a situação da sociedade brasileira. De acordo com Saviani (2011, p. 317, itálicos nosso):

A expressão "educação popular" assume, então, o sentido de uma educação do povo,
pelo povo e para o povo, pretendendo-se superar o sentido anterior, criticado como
sendo uma educação das elites, dos grupos dirigentes e dominantes, para o povo,
visando a controlá-lo, manipulá-lo, ajustá-lo à ordem existente.

Nota-se que essa inversão estabelecida não se dá apenas no plano do significado, deslocado da prática social. Mas, ao contrário, pois ocorre por meio de uma inversão do ato político no âmbito do processo educativo. Nesse sentido, passa a corroborar com o ideal de atribuir a educação aos interesses dos subalternos, principalmente, no sentido de contribuir com a transformação social, via movimento de conscientização crítica do indivíduo trabalhador, de modo que o mesmo fosse capaz de compreender sua situação social e, por meio de uma 
coletividade, pudesse estabelecer mecanismos para a superação da sociedade brasileira conservadora.

E, à guisa de ilustração e destaque, corroboramos com Lima (2018) e Saviani (2011) que a orientação de Paulo Freire foi extremamente complexa e seguida pelos principais movimentos desse período - como os Centros Populares de Cultura, por exemplo - e que teve enorme repercussão no Brasil e no exterior. Afinal, na acepção de Lima (2018, p. 48-49):

\begin{abstract}
Em um período de transição ainda inacabada para a sociedade urbano industrial, a educação popular por intermédio da práxis freireana deixou de ser um projeto de elites, expressando no campo da pedagogia a práxis dos povos oprimidos enquanto lutam por sua libertação, entendida como a superação dos entraves que inviabilizam o desenvolvimento dos homens enquanto trabalham, ou o seu "ser mais".
\end{abstract}

É nesse âmbito que compreendemos que a teoria pedagógica histórico-crítica pode contribuir com o projeto social que tenha como objetivo a transformação social. Tanto para as escolas, bem como para os mais diversos espaços de formação crítica da classe subalterna, a pedagogia histórico-crítica fornece elementos teórico-metodológicos suficientes para que os professores possam efetivar sua função.

A partir dessa discussão, no momento seguinte serão expostos elementos pedagógicos, a partir de uma visão materialista, histórica e dialética, que podem contribuir para a formação de professores na perspectiva da educação popular do povo e para o povo. Para isso, de antemão, o professor deve estar capacitado, por meio do conhecimento científico, como um instrumento para uma vigilância crítica da atual sociedade, isto é, que perspective e efetive ações concretas para a transformação social.

\title{
4 Formação de professores em proveito da educação popular do povo e para o povo
}

A concepção aqui adotada sobre a educação popular do povo e para o povo tem como escopo a prática educativa manifestada nos diversos espaços, a partir de uma atividade educativa sistematizada. Trata-se de uma educação que busca contribuir para a promoção humana dos indivíduos, em especial, da classe subalterna. Ela procura, então, atender os interesses dessa classe social que é, em última instância, a transformação social.

Porém, na esfera do modo de produção capitalista, a classe subalterna é excluída da condição para a promoção humana no humano, isto é, os trabalhadores não têm acesso ao conhecimento historicamente sistematizado. Ademais, a sua função social nada mais é do que produzir mercadoria em detrimento da sua existência enquanto ser humano. 
A educação popular do povo e para o povo tem sua finalidade na atividade educacional sistematizada, ou seja, tal atividade não coincide com a atividade espontânea que o trabalhador, na imediaticidade das suas ações, realiza. Trata-se da compreensão da situação atual da realidade concreta e, por conseguinte, na efetividade de transformação.

O professor, destarte, assume posição cabal nesse processo, pois é por sua contribuição que o trabalhador terá condições de se apropriar do conhecimento historicamente sistematizado e, por consequência, de compreender da realidade concreta, justificando a necessidade da transformação social. Gramsci (2001, p. 20) aponta que “[...] a elaboração das camadas intelectuais na realidade concreta não ocorre num terreno democrático abstrato, mas segundo processos históricos tradicionais muito concretos". Com isso, as diferentes maneiras de interferir no processo formativo dos indivíduos preconizam níveis distintos de especialização intelectual, impondo sempre uma relação entre os intelectuais e o processo de produção e de trabalho de maneira “[...] 'mediatizada', em diversos graus, por todo o tecido social, pelo conjunto das superestruturas, do qual os intelectuais são precisamente os "funcionários"”.

Nesse sentido, a pedagogia histórico-crítica apresenta embasamentos que compreendem a prática educativa como uma atividade sistematizada e, por sua vez, que devem incidir no desenvolvimento do indivíduo, fazendo com que ele possa intervir no mundo real também por meio de atividades sistematizadas. Em outras palavras: a intervenção do ser humano no mundo real deve ser realizada de maneira que ele possa compreender a essência desse mundo e, de maneira intencional e criativa, nele possa intervir em proveito de uma transformação social.

Com efeito, a formação de professores, direcionada para a condição de prática educativa acima citada, deve partir da constante investigação e descoberta sobre o ser humano na sua realidade existencial e, por conseguinte, buscar aprofundar ainda mais essa descoberta. Ou seja, implica compreender as questões mais específicas da estrutura desse ser humano na sua realidade existencial. Dessa forma, pode-se consubstanciar o professor em formação para atuar por meio de uma atividade educacional sistematizada (SAVIANI, 2012).

Para tanto, quando direcionamos um primeiro olhar sobre o ser humano podemos chegar ao consenso de que se trata de um corpo que se relaciona com outros corpos no interior do mundo. Seguindo a reflexão de Saviani (2012), trata-se de um corpo inserido em outro que é o próprio mundo. O ser humano, portanto, é fortemente influenciado pelas leis físicas. Justificase, então, levar em consideração o lugar onde o ser humano está inserido para poder educá-lo.

Ressalte-se que a educação não é um ato apenas espiritual, ela tem como função contribuir também no sentido de fazer com que o ser humano se situe no meio físico em que está inserido. E, com isso, contribua para que ele possa extrair, de forma consciente, o máximo 
possível de condições existentes daquele meio físico. Aqui podemos observar como é importante trazer à tona os elementos, por exemplo, de ciências como a agronomia, a geografia, etc. para elucidar problemas levantados no interior da atividade educativa sistematizada.

Entretanto, nota-se que nos referimos a determinadas ciências no sentido de extrair elementos delas para contribuir na elucidação de um problema estabelecido pedagogicamente. $\mathrm{O}$ que, no presente caso, seria situar e fazer com que o ser humano extraia as condições pertinentes do meio físico em que ele está inserido.

Com efeito, a partir de Saviani constatamos um primeiro dado sobre a estrutura do ser humano: o a priori ${ }^{2}$ físico. Porém, o autor complementa que o ser humano não é apenas um corpo físico, ou seja, o ser humano não tem total dependência do contexto físico. Logo, restringir a educação somente a uma suposta promoção material é negar a própria função da educação. "Nesse contexto, a determinação de objetivos e ideais educativos, a capacidade de previsão e o desencadeamento de um processo orientado, tornam-se impraticáveis" (SAVIANI, 2012, p. 33-34).

O que se constata nesse primeiro olhar sobre a estrutura do ser humano é que, no tocante à educação, não podemos desconsiderar a realidade física do aluno. Desse modo, a perspectiva física deve ser levada em consideração no ato educativo do indivíduo. Não se trata de um materialismo pedagógico (no sentido de evidenciar somente a matéria), mas sim de extrair elementos pertinentes, específicos de tais ciências, para elucidar questões pedagógicas no âmbito da atividade educativa sistematizada.

Mas, a estrutura do ser humano não se dá somente pelo a priori físico. É necessário levar em consideração que o ser humano não é um corpo idêntico a qualquer outro corpo. Pelo contrário, é um corpo que possui composições específicas. De acordo com Saviani (2012), tratase de um corpo vivo e que interfere e é interferido de forma global, estabelecendo condições de coordenar e elaborar suas ações. Logo, é pertinente conhecer esse corpo, dada a complexidade do conjunto dos seus órgãos, bem como o seu funcionamento. Trata-se de levar em consideração, no âmbito da estrutura do ser humano, o a priori biológico.

Em contrapartida, seguindo as orientações do autor supracitado, atentamos para um segundo pressuposto a ser levado em consideração na atividade educacional sistematizada: a realidade física (a priori físico) e a realidade biológica (a priori biológico) do educando. A atividade educacional sistematizada não se restringe nem ao a priori físico, tampouco ao $a$ priori biológico, mas ambos complementam um núcleo que é a estrutura do ser humano.

\footnotetext{
${ }^{2}$ Saviani esclarece que o conceito de a priori não tem, nessa análise, “[...] o sentido do a priori lógico (como em Kant), nem do a priori no sentido cronológico. Trata-se do a priori existencial, ou seja, as condições necessárias de possibilidade da existência humana" (SAVIANI, 2012b, p. 33).
} 
Seguindo adiante, com base na análise de Saviani (2012) compreendemos que os dois pressupostos estabelecidos até o momento permitem verificar que o ser humano está inserido em um ambiente exterior. Mas, podemos perceber que também existem questões internas do ser humano, e que tais questões constituem uma maneira complexa de apreender a realidade externa. Trata-se, portanto, do a priori psicológico, que também compõe a estrutura humana.

Nesse a priori há uma importância ímpar no tocante à atividade educacional sistematizada, uma vez que o processo de aprendizagem depende do a priori psicológico do ser humano. Assim, é por meio da aprendizagem que o ser humano apreende, subjetivamente, a realidade objetiva. Destarte, para que tal atividade possa ser eficiente deve-se levar em consideração tal a priori. Não se trata, por exemplo, de um psicologismo pedagógico, mas de identificar elementos pertinentes ao campo de estudo da psicologia, de modo que possa contribuir na atividade educacional sistematizada.

Consequentemente, ao levar em consideração, no âmbito da atividade do professor, a realidade física, biológica e a realidade psicológica do educando, se estabelece uma unidade dos três a priori que compõem a estrutura natural do ser humano.

Todavia, ao contrário de uma concepção pedagógica naturalista, tal como propunha Rousseau (à guisa de ilustração), a estrutura do ser humano não se restringe apenas aos seus aspectos naturais, visto que o ser humano não é somente um corpo adaptativo ao meio, mas sim um corpo que está situado em um determinado contexto histórico-social, tornando-se produto e produtor desse mesmo contexto. O ser humano nasce num determinado meio hominizado, isto é, cujo ambiente natural foi transformado por seus predecessores.

A estrutura do ser humano comporta, portanto, uma quarta condição de possibilidade de sua existência. Trata-se do a priori cultural do qual o ser humano depende, inteiramente, para se constituir. Tal a priori é de suma importância, ao ponto de influenciar todos os demais. Nesse sentido, tudo aquilo que o ser humano faz, seja no âmbito físico, biológico ou psicológico, está sendo influenciado pelo a priori cultural. Vejamos a elucidação de Saviani (2012, p. 41) ao analisar e explicitar a importância do a priori cultural:

Pode-se dizer que é justamente na medida em que o homem é formado por um certo meio, por um certo ambiente, que ele fica familiarizado com esse ambiente. Isso se verifica em relação aos mais diversos domínios: música, pintura, religião, vestimentas etc. Gosta-se mais deste ou daquele tipo de música, deste ou daquele tipo de pintura, de acordo com o grau de familiaridade que se tem com os seus valores culturais. Portanto, o homem, numa larga medida, se deixa moldar pelo meio em que se encontra. A psicologia das pessoas, o seu modo de ver as coisas, são influenciados pelo ambiente cultural. Para explicar esse fenômeno, os pensadores contemporâneos costumam se referir à historicidade, o que quer dizer que, de algum modo, o homem é resultado da História: "já que sou um corpo, forçosamente sou situado, vivo num certo meio, certa cultura; e essa historicidade influencia tudo o que faço". 
Levando em consideração o posicionamento supradito, concluímos que a aprendizagem é importante para o desenvolvimento da estrutura do ser humano na sua totalidade. Destaquese, porém, que a aprendizagem que aqui mencionamos está calcada nos preceitos da pedagogia histórico-crítica, pela qual o educando deve se apropriar daquilo que de mais complexo a humanidade produziu no decorrer da história. Assim, ele passa a ter o domínio das máximas objetivações humanas e, por consequência, se familiariza com aquilo que de mais avançado o conjunto de seres humanos produziram historicamente e desenvolveram socialmente.

O a priori cultural, nesse sentido, é fundamental tanto para a estrutura do ser humano, como para a atividade sistematizada do professor. Logo, por se tratar de um a priori complexo, é abordado por várias vertentes (política, história, antropologia, economia, sociologia, etc.).

Observa-se que não é possível deixar de lado o a priori cultural no ato de educar os educandos, assim como não é possível excluir os demais a priori mencionados anteriormente. Porém, o que vimos até o momento é que a estrutura do ser humano (por meio dos a priori físico, biológico, psicológico e cultural) é determinada e limitada.

O que fizemos até aqui foi procurar compreender os quatro a priori que constituem, de acordo com Saviani (2012), o aspecto empírico da estrutura do ser humano, analisando, então, o ser humano como um ser situado. Contudo, se reduzirmos a estrutura do ser humano apenas a esse aspecto, a própria atividade educativa resulta impossível. Com efeito, se o ser humano for totalmente determinado pela situação em que se encontra inserido como o professores, ele poderá intervir junto ao educando para educá-lo?

Mas, no esforço de exercer uma análise sobre a estrutura do ser humano, podemos compreender que ele é um ser situado e, ao mesmo tempo, é um ser que reage às situações estabelecidas pela realidade concreta. Essa reação se dá no campo pessoal, ou seja, ao se deparar com algumas situações estabelecidas na realidade concreta, a partir das quais o ser humano pode tanto optar por aceitá-las, como recusá-las ou então transformá-las.

Com efeito, constatamos que o ser humano tem a condição de superar a situação na qual está inserido. Ele apresenta condições concretas para intervir, de forma pessoal, na situação para acatá-la, rejeitá-la ou transformá-la. Nota-se, portanto, que o ser humano é um ser vivo autônomo e livre. E é, justamente, pela sua condição de liberdade que, de acordo com Saviani (2012), configura-se o segundo aspecto da estrutura do ser humano, isto é, o aspecto pessoal.

Ambos os aspectos, o empírico e o pessoal, são fundamentais, porém não são compatíveis entre si, uma vez que no aspecto empírico o predomínio se expressa na condição determinista e já no aspecto pessoal o predomínio se expressa na condição de liberdade do ser humano. 
O aspecto pessoal está contido de inúmeras maneiras nas ações do ser humano: na sua forma de falar, de se alimentar, de caminhar, etc. O indivíduo, por exemplo, adere a determinada crença religiosa e passa a ser responsável por sua crença. Em suma, o aspecto pessoal, na dicção de Saviani (2012, p. 46, itálicos no original), “[...] é o aspecto do engajamento; o sujeito se engaja, se envolve pessoalmente, toma posição perante a situação”. Nesse sentido, o aspecto pessoal pode ser compreendido também como "[...] aspecto voluntário, pois salienta que o homem é um ser capaz de tomar decisões, capaz de querer, de escolher, de fazer opções e engajar-se por elas".

A estrutura do ser humano extrapola a sua condição de estar, passivamente, numa dada situação. Ele, o ser humano, enquanto indivíduo pessoal tem condições de "[...] dominar a situação, de se afastar ou intervir, de decidir, escolher, arriscar, lançar-se no vazio, mas também assumir suas escolhas, engajar-se por elas, responsabilizar-se" (SAVIANI, 2012, p. 50). Ora, se o ser humano é capaz de intervir na situação, de decidir, de engajar-se, responsabilizar-se, então o professor pode intervir na situação do educando e assumir a responsabilidade por sua educação. Assim, na medida em que a estrutura do ser humano comporta, além do aspecto empírico, o aspecto pessoal, fica resolvido o problema da possibilidade da educação em termos gerais.

Contudo, o problema que surge, agora, é o da legitimidade da educação (da atividade educacional sistematizada), pois se o aspecto pessoal evidencia a liberdade humana, esta é um atributo tanto do professor como do educando, já que ambos são seres humanos. Então, com que direito o professor interfere na vida do educando pretendendo orientá-lo e até mesmo mudar seu modo de viver e de pensar?

Para responder esta questão se faz necessário prosseguir na análise da estrutura do ser humano, a fim de encontrarmos algo para além dos aspectos empírico e pessoal, e que permita resolver o problema da legitimidade da educação.

Para isso, Saviani (2012, p. 51, itálicos nossos) nos indica o terceiro aspecto da estrutura do ser humano: o aspecto intelectual (aperceptivo). Quanto a este terceiro aspecto, o autor argumenta que o ser humano "[...] pretende transcender a situação (aspecto empírico) e os pontos de vistas individuais (aspecto pessoal), para julgar de um modo objetivo e absoluto. É este o aspecto que possibilita a comunicação". Esse é o aspecto da transcendência. A partir dele o ser humano pretende superar as limitações da situação e da visão pessoal, colocando-se numa perspectiva universal e se tornando capaz de transcender suas próprias posições pessoais para compreender a situação e posições das outras pessoas, por meio de uma comunicação intersubjetiva. 
Ora, se o ser humano é capaz de transcender sua própria situação e opções pessoais para se colocar na perspectiva dos outros seres humanos, então o professor pode, legitimamente, intervir junto ao educando e, levando em conta sua situação e opções pessoais, promover seu desenvolvimento. Fica, assim, resolvido o problema da legitimidade da atividade educacional sistematizada. Trata-se, por conseguinte, como condição da educação popular do povo e para o povo, de um ato político da educação em proveito dos interesses da classe subalterna.

A realidade do aspecto intelectual pode ser compreendida, em linhas gerais, como a consciência do ser humano. Apreende-se, então, que a estrutura do ser humano é composta pela relação de três aspectos: empírico (físico, biológico, psicológico e cultural), pessoal (liberdade e responsabilidade) e intelectual (consciência).

A consciência, por sua vez, possibilita que o ser humano possa compreender os fenômenos, os objetos, etc. Ela se caracteriza por duas maneiras: irrefletida (espontânea) ou refletida (tematizada). A consciência irrefletida apreende o objeto, o fenômeno, apenas de forma superficial e fragmentada. Trata-se, portanto, de uma maneira de se deter rapidamente o que está no campo de visão, isto é, aquilo que realizamos cotidianamente e que, de alguma maneira, ficou quase automatizado, a tal ponto de não nos determos para a compreensão na sua plenitude.

Porém, essa consciência irrefletida pode passar a se tornar um ato de conhecimento sobre determinado objeto ou fenômeno. Passa-se, então, ao tipo de consciência refletida. Esse tipo de consciência diz respeito à forma como o ser humano passa a compreender os dados da realidade concreta de forma mais coesa, radical e aprofundada.

O ser humano tem a condição de agir por meio de um desses dois tipos de consciência e, assim, estabelecer a sua linha de ação ou o seu projeto a ser executado. Sendo assim, consciência espontânea (irrefletida) e consciência refletida estão sempre relacionadas no que se refere ao apreender o real. Logo, o ser humano pode se aprofundar cada vez mais a compreensão da situação com a qual se depara. Portanto, no tocante à estrutura do ser humano, conclui-se que a possibilidade concreta do indivíduo transcender a situação posta e as alternativas pessoais se dá por meio da consciência, mais precisamente, por meio da consciência refletida (reflexão).

A reflexão é uma espécie de pensamento num segundo grau. Trata-se de um pensamento consciente de si mesmo. "Refletir é o ato de retomar, reconsiderar os dados disponíveis, revisar, vasculhar numa busca constante de significado. É examinar detidamente, prestar atenção, analisar com cuidado (SAVIANI, 2013a, p. 20). 
Não obstante a importância do aspecto intelectual, a atividade educacional não deve se centrar apenas nesse aspecto em detrimento dos demais. Mas, certamente, a sua importância é imensurável, principalmente por sua realidade estar alocada na comunicação.

Sinteticamente, levando em consideração os três aspectos para a educação, podemos compreender que a sua legitimidade, enquanto condição concreta de contribuir para a promoção do ser humano, é, de fato, possível.

\begin{abstract}
Uma vez que é possível a pessoas livres (e só a pessoas livres o é) o fato da comunicação, então a educação, na medida em que se constitui nessa comunicação entre pessoas livres em graus diferentes de maturação humana, será realmente uma promoção humana de parte a parte, tanto do educando como do educador. Se eu, enquanto educador, sou capaz de transcender a minha situação e opções pessoais para me colocar no ponto de vista do outro (o educando) e se a recíproca vai se tornando cada vez mais possível através do ato educativo, então não há violação da liberdade, mas exercício dela; não há desrespeito à pessoa do educando, mas respeito. Portanto, a atividade educacional é legítima (SAVIANI, 2012, p. 58, itálicos nosso).
\end{abstract}

O futuro professor, portanto, deve compreender, de maneira coesa, radical e por meio de uma vigilância crítica, o educando como um ser situado em determinada realidade. Nesse sentido, procurando identificar e compreender as especificidades do aspecto empírico (aquilo que compõe sua a estrutura natural) no que se refere às situações da realidade concreta. Há a necessidade de compreendê-lo como um ser capaz de estabelecer um ponto de vista sobre as questões situacionais, isto é, trata-se do aspecto pessoal que se constitui pelas condições de responsabilidade e liberdade do aluno. Nos referimos, portanto, ao processo de comunicação entre professor e educando, capaz de interferir na consciência do aluno, ou seja, capaz de interferir no aspecto intelectual. Destarte, se propondo a efetivar um salto qualitativo da compreensão do aluno sobre as questões situacionais para atingir o momento catártico do aluno (transição da consciência irrefletida/espontânea para a consciência refletida) e, assim, contribuindo para a atividade sistematizada dos educandos.

É nesse sentido que a prática educativa passa a contribuir, efetivamente, para a promoção do educando em proveito da transformação social. Assim será possível que o mesmo tenha condições de compreender e intervir na situação atual da realidade concreta e, por conseguinte, atuar para a transformação social. Logo, a formação de futuros professores deve ter como essência a condição cabal de compreender a estrutura do ser humano, a fim de efetivar no bojo da sua atividade educacional sistematizada a condição de conscientizar, principalmente, os membros da classe subalterna para uma transformação radical da situação atual da realidade concreta.

Afinal, conforme Gomez (2012, p. 73): 
Ao pensar nos sujeitos individuais e coletivos configurados na atual sociedade de classes e, mais precisamente, nos trabalhadores coletivos produzidos nos diversos processos de trabalho, podemos concluir que a única via para ultrapassar as diversas manifestações de alienação será a transformação radical da sociedade. Essa mudança radical, essa emancipação se dará no momento em que se criem as condições favoráveis para que o conjunto dos trabalhadores, dos produtores, assumam a direção da produção, o que implicitamente representa tomar a direção da sociedade.

Uma das estratégias cabais para que essa condição possa ocorrer é por meio da educação, isto é, por meio da atividade educacional sistematizada. Isso acarretará em uma conscientização de classe que possa engendrar uma articulação crítica entre os subalternos, ou seja, a sistematização das ações do indivíduo a partir de uma nova consciência (refletida) sobre a realidade concreta.

Portanto, a formação de novos professores perpassa, por conseguinte, por uma formação política, ou melhor, numa acepção marxista, pelo “[...] encadeamento de consciência da situação com a ação prática modificadora" (FERNANDES, 2010, p. 140). Pois, é justamente esse encadeamento que o professor, via uma atividade educacional sistematizada, promoverá na formação dos membros da classe subalterna.

\section{Considerações finais}

Neste texto procuramos apresentar elementos sobre a formação de professores na perspectiva da educação popular, isto é, uma educação que atenda os interesses da classe subalterna que é, em última instância, a transformação social.

Isto porque, conforme nos lembra Fernandes (2010), há uma relação intrínseca entre consciência pedagógica (do professor) com os problemas provenientes da sociedade por meio de uma nova maneira de ação prática. Assim, é possível contribuir com uma transformação substantiva do modo de educar para o consenso, pois para além de uma análise espontânea da situação social atual, preconiza-se a ação prática transformadora, desencadeada por uma consciência teórica e prática em um sentido revolucionário. 


\section{Referências}

ALVES, G. Trabalho e subjetividade: o espírito do toyotismo na era do capitalismo manipulatório. 1. ed. 1. reimpr. São Paulo: Boitempo, 2012.

FERNANDES, F. O desafio educacional. In: OLIVEIRA, M. M. Florestan Fernandes. Recife: Fundação Joaquim Nabuco; Editora Massangana, 2010. p. 119-140.

FRIGOTTO, G. Trabalho, conhecimento, consciência e a educação do trabalhador: impasses teóricos e práticos. In: GOMEZ, C. M. et al. Trabalho e conhecimento: dilemas na educação do trabalhador. 6. ed. São Paulo: Cortez, 2012. p. 19-38.

GOMEZ, C. M. Processo de trabalho e processo de conhecimento. In: GOMEZ, C. M. et al. Trabalho e conhecimento: dilemas na educação do trabalhador. 6. ed. São Paulo: Cortez, 2012. p. 59-82.

GRAMSCI, A. Cadernos do Cárcere: Os intelectuais; O princípio educativo; Jornalismo.vol. II. 2. ed. Rio de Janeiro: Civilização Brasileira, 2001.

LIMA, M. R. A pedagogia da libertação no contexto da reestruturação capitalista: da "escola com os pés no chão" aos desafios da educação popular no labirinto dos "Novos Movimentos Sociais". 2018. 471 f. Tese (Doutorado em Educação), Faculdade de Educação, Universidade Estadual de Campinas, 2018.

SAVIANI, D. História das ideias pedagógicas no Brasil. 3. ed. Campinas: Autores Associados, 2011.

SAVIANI, D. Educação brasileira: estrutura e sistema. 11. ed. rev. Campinas: Autores Associados, 2012.

SAVIANI, D. Educação: do senso comum à consciência filosófica. 19. ed. Campinas: Autores Associados, 2013a.

SAVIANI, D. Pedagogia histórico-crítica: primeiras aproximações. 11. ed. rev. Campinas: Autores Associados, 2013b.

SAVIANI, D. História do tempo e tempo da história: estudos de historiografia e história da educação. Campinas: Autores Associados, 2015. 